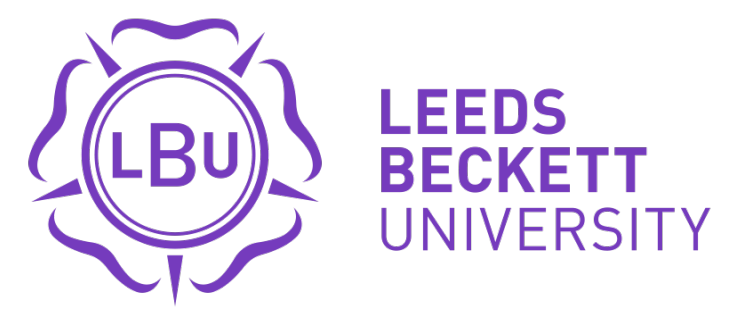

Citation:

Musgrave, J and Woodward, S (2016) Ecological Systems Theory Approach to CSR: Contextual perspectives from meeting planners. Event Management: an international journal, 20 (3). pp. 365-381. ISSN 1943-4308 DOI: https://doi.org/10.3727/152599516X14682560744712

Link to Leeds Beckett Repository record:

https://eprints.leedsbeckett.ac.uk/id/eprint/1537/

Document Version:

Article (Published Version)

Creative Commons: Attribution 4.0

Date of Acceptance: 17 Nov 2014

The aim of the Leeds Beckett Repository is to provide open access to our research, as required by funder policies and permitted by publishers and copyright law.

The Leeds Beckett repository holds a wide range of publications, each of which has been checked for copyright and the relevant embargo period has been applied by the Research Services team.

We operate on a standard take-down policy. If you are the author or publisher of an output and you would like it removed from the repository, please contact us and we will investigate on a case-by-case basis.

Each thesis in the repository has been cleared where necessary by the author for third party copyright. If you would like a thesis to be removed from the repository or believe there is an issue with copyright, please contact us on openaccess@leedsbeckett.ac.uk and we will investigate on a case-by-case basis. 


\title{
ECOLOGICAL SYSTEMS THEORY APPROACH TO CORPORATE SOCIAL RESPONSIBILITY: CONTEXTUAL PERSPECTIVES FROM MEETING PLANNERS
}

\author{
JAMES MUSGRAVE* AND SIMON WOODWARD† \\ *Department of Food and Tourism, Manchester Metropolitan University, Manchester, UK \\ †School of Events, Tourism and Hospitality, Leeds Beckett University, Headingley Campus, Leeds, UK
}

\begin{abstract}
Business reputation, competitive advantage, differentiation, and regulatory adherence are all factors that are pushing corporate social responsibility (CSR) center stage within the international meetings industry. However, attempts to simplify what is essentially a complex and contextual driven movement through certification and guides has created an incomplete understanding of the salient issues; contemporaneously ignoring contextual variables rather than acknowledging these and the impact these variables have on CSR practice and acceptance. The purpose of this article is to explore the contextual debate of CSR adaptation and practice within the meetings sector within a framework of an ecological systems theory. The authors applied a constant comparison process across 90 interview transcripts in order to establish a rigorous audit trail of analysis. Eight practices were identified: Green Technology, Legislation, Transparency and Reliability, Nonfinancial Donations, Workforce, Community Engagement, Supply Chain Management, and Volunteer Labor. These eight practices were then applied to the constructs of an ecological systems model and an exploration of contextual factors was considered. In recognizing a systems approach to CSR there is an acceptance that there is not one best method and that different values, implementation approaches, and evaluation mechanisms of CSR can lead to similar results.
\end{abstract}

Key words: Corporate social responsibility (CSR); Context; Meeting planners; Ecological systems theory; Events management

Introduction

Benefits such as enhanced business reputation, competitive advantage, differentiation, and regulatory adherence are all factors that are pushing corporate social responsibility (CSR) center stage within almost every sector of the global economy, including the international meetings and events industry. However, the rate and scale of adoption of CSR practices by the meetings industry has been

Address correspondence to James Musgrave, Senior Lecturer in Events Management, Department of Food and Tourism, Hollings Faculty, Manchester Metropolitan University, Room 2.26, Cavendish Building, Cavendish Street, Manchester, M15 6BG, UK. Tel: 0161247 2736; E-mail: j.musgrave@mmu.ac.uk 
shown to vary considerably (Musgrave, Mulligan, Woodward, Kenyon, \& Jones, 2012). Unfortunately, this apathy towards CSR rests against a rise in the prominence of the global meetings sector, which is now estimated to be worth in excess of \$1.1 trillion (UFI, 2012). Patently any increase in demand and supply results in an increase in consumption and proliferation of impacts. How the meeting planners, venues, and their clients address these issues in the future is key to the long-term credibility of the sector.

Standards, guides, and documentation related to CSR and sustainable business best practice are widely available (see Fig. 1) particularly from industry associations. For example, the Green Meeting Industry Council purport CSR is an aspirational and long-term commitment to ethical and highly valuable business practice. At the same time the mission of the International Special Events Society (ISES) is to educate, advance, and promote "principles of professional conduct and ethics," while Meeting Professionals International (MPI) is committed to providing members with applied examples of sustainability in practice. The role of Exhibition and Event Association of Australia (EEAA) is to promote sound health and safety and ethical practice and help member businesses to grow profitably, while the Association of Exhibitions and Events (IAEE) concentrate upon honesty and integrity as a brand throughout their documentation. This is not an exhaustive list but highlights the holistic nature of corporate social responsibility and the diverse impact an event business has on its internal and external environment.

Attempts to simplify what is essentially a complex and contextual driven movement through taxonomies, certification, guides, and definitions have received low levels of recognition in the meetings industry (Merrilees \& Marles, 2011; Musgrave et al., 2012). In striving for simplicity, many event management publications focus upon impact assessments or environmental practices and ignore the contextual debates found within CSR literature. Moreover, event management publications tend to be case study based and have overlooked the complexities that CSR presents. Thus, the taxonomies, models, and findings that advocate generic, homogenous, and indeed ubiquitous terms offer little incentives for industry to implement and connect with. Unfortunately, the outcome for many practitioners is an incomplete understanding of the salient issues; contemporaneously ignoring contextual variables rather than acknowledging these and the impact these variables have on CSR practice and acceptance.

The purpose of this article is to explore the contextual debate of CSR adaptation and practice within the meetings sector within a framework of an ecological systems theory. Moreover, we want to understand why uptake and practice of CSR is variable across the sector.

Traditionally, a systems theory perspective is a standpoint for conceptualizing the changing person or organization in relation to a changing environment, more specifically the social, physical, and psychological environs. This contextual debate somewhat mirrors that of C. A. Williams and Aguilera (2008), who suggest that attitude towards CSR is influenced by national cultural norms, organizational culture, and industry norms. Accordingly, the effects of individual and environmental factors upon CSR expectations and practices vary in strength and direction. Using Bronfenbrenner's seminal work in mapping ecological systems theory on human development, the premise of this conceptual article accepts the effects of individual and environmental factors upon CSR expectations and practices is synergistic and multidirectional.

The discussion draws upon the findings of a program of interviews with some 90 representatives of the meetings industry conducted as part of a broader, industry-focused research project looking at the value of CSR to the meetings industry (Musgrave et al., 2012).

\section{The Contextual Nature of CSR}

\section{Scope of CSR}

Corporate social responsibility has often proved to be a difficult aspect of contemporary corporate behavior to define as a single concept, partly because of the many different activities that can be encompassed in the term and partly because of the varied outputs and benefits that can be associated with this increasingly ubiquitous term. Indeed, difficulty in defining CSR has hampered practitioner adoption and presents problems in comparing academic studies and empirical activities (Dahlsrud, 2008). The rapid 


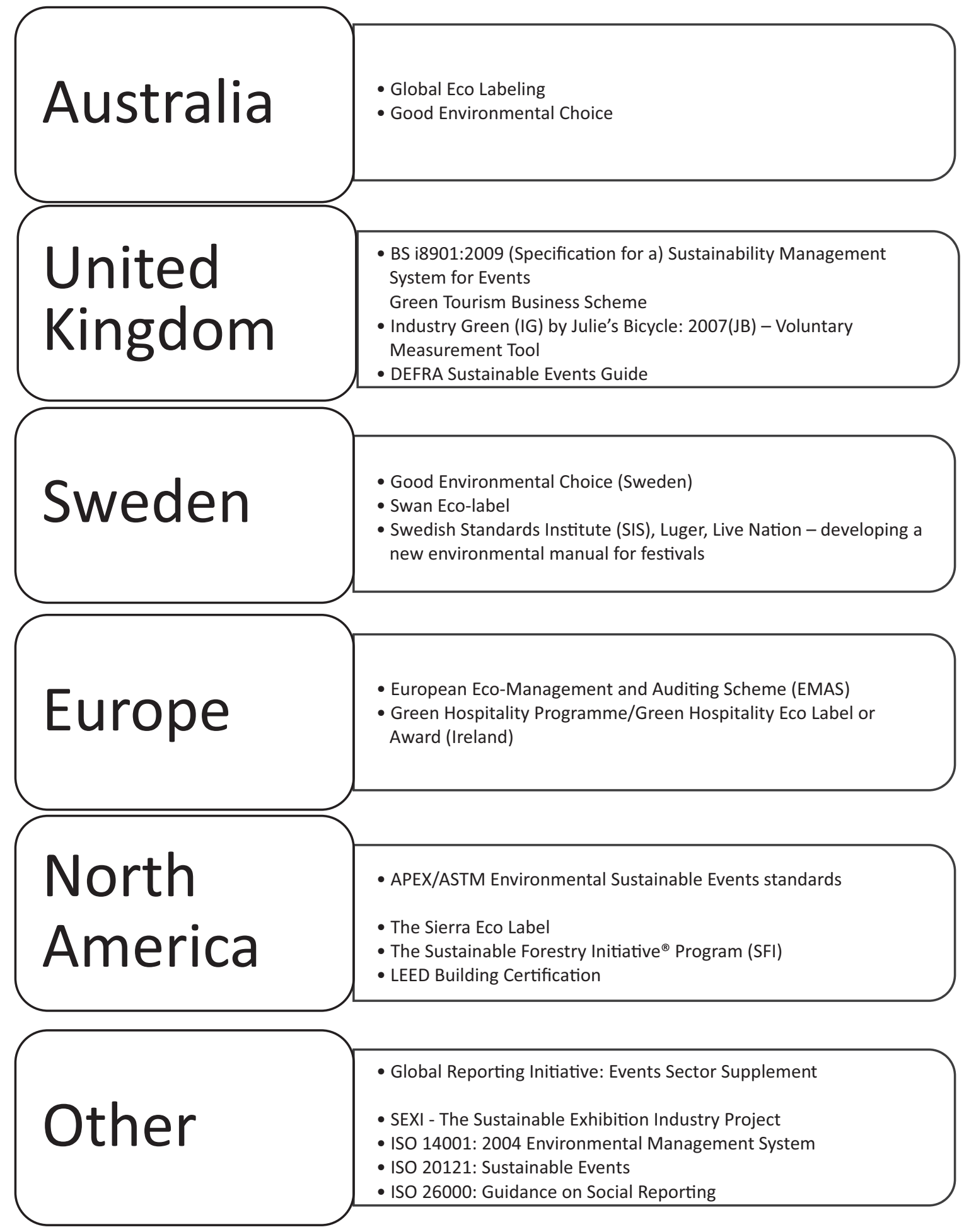

Figure 1. Sustainable standards and guides for event managers. Adapted from Tinnish (2013). 
development of CSR in recent years has further segregated practitioners' commitment towards CSR initiatives. For example, Marrewijk (2003) claims that there are now over 300 CSR codes, principles, performance standards, and management standards developed by governments, business associations, or academia, not mentioning a number of individual company's codes of conduct or reporting initiatives. These "own brand" approaches to CSR practice have ballooned such statistics and more often than not there is a discrepancy between what practitioners say they do and what they actually do. Consequently, the profuse manifestation of CSR practices is couched in political and cultural zeitgeist, rather than 300 distinct schools of theory, constructs, and practice. Whether or not these represent different schools of thought, it does imply that that there are widespread variations in practice and adaption.

These variations are also evident in the theoretical foundations. Zink (2007) recommends using CSR as a social strand of the sustainable development (SD) concept whereby CSR is focused especially on organizational activities and the consideration and realization of stakeholder expectations within national society and the local community. Authors such as Banerjee (2008); Montiel (2008); Stubbs and Cocklin (2008); and Rees (2002) relate CSR to the development of value creation and approaches that make CSR economically worthwhile to organizations. In support of value creation Málovics, Csigéné, and Kraus (2008) conclude that the role of CSR can be split into four levels: commercial self-interest, expanded self-interest with immediate benefit, expanded self-interest with long-term benefit, and promotion of the common good. In furthering the concept of organization "value" Fairbrass (2006) harks back to the neo-classical economists such as Friedman (1962) and also notes Carroll's (1999) view that social goals are valuable in their own right and not subordinate to economic goals. These historical views of CSR can be categorized into three areas (Falck \& Heblich, 2007):

- Shareholder approach: social responsibility of business is to increase its profits.

- Stakeholder approach: balance a multiplicity of stakeholders' interests that can affect or are affected by the achievement of an organization's objectives.

- Societal approach: to serve constructively the needs of society - to the satisfaction of society.

In viewing the historical perspectives of CSR Katsoulakos, Koutsodimou, Matraga, and Williams (2004) identified drivers that may enable a clearer understanding of CSR approaches and the added value to stakeholders. Fundamentally, two CSR dimensions were taken from these antecedents:

- CSR is part of a new vision of the world based on a global partnership for sustainable development.

- CSR represents a business management approach that should provide in the long run better value for the shareholders as well as for other stakeholders.

In dealing with disparate CSR approaches Málovics et al. (2009) divides CSR practice into three types: must responsibilities; should responsibilities and can responsibilities, depending upon market conditions, competitor action/initiatives, and consumer response. Here organizations consider CSR as an important mechanism to manage risk/ reputation and improve community benefits through increased sale. Yet this allegiance to Friedman's shareholder approach and corporate responsibility ignores microsocietal questions such as the impacts that businesses can have on communities through the way they operate.

Schwartz and Carroll (2003) are of the opinion that CSR theory should relate to resource allocation of an organization, and view investment towards CSR as a mechanism for product differentiation. For example, the manufacture of products or delivery of service should be supported by processes that embody CSR, coupled with additional support services and guidance attributed to CSR. Thus, according to Schwartz and Carroll (2003) service differentiation can be achieved through exploitation of the appeal of CSR attributes to key segments of the market. In support Wan-Jan (2006) comments upon those who take CSR as a business strategy do so under the assumption that compliance will achieve sustainable profitability; equally serving the central norm of shareholder return while maintaining business and generating employment 
to the local society. Once again these approaches reflect the traditional views of CSR as a tool for business performance.

Nevertheless, Ketola (2007) presents a strong ethical discourse towards the study of sustainable management within organizations. According to Musgrave (2011), Ketola argues that adding economic value to CSR action reduces the moral validity. Moreover, implementing CSR initiatives from a "what do I get out of it" viewpoint perverts the foundation of corporate social responsibility. Key to her viewpoint is this simple question; why should companies have the right to do harm to people and the planet? Yet the neoclassical approach professes that businesses do more good than harm to society. Is there then an opportunity for an equilibrium that meets societal needs without compromise? Or has CSR become purely aspirational?

\section{Contextual Practice}

In acknowledging the continuing debate and criticism of CSR, Marrewijk (2003) sees this impacting upon the practice of CSR at national and international levels. More specifically, there exists misperception surrounding the relevant indicators of CSR; scope of voluntary practice; reporting mechanism; differing national and international terminology; and accepted religious responsibility. For example, Spitzer (2009) argues that understanding of CSR differs from country to country-they differ in the degree of voluntary or regulatory obligation that form codes of conducts that supposedly guide business practices within national frameworks. In a similar vein to Chapple and Moon (2005), Spitzer (2009) presents variances of CSR meaning, translation, and implementation in Asia arguing that while Western European governments play an important role in guiding, publishing, and demanding CSR and reporting; East Asian governments tend to consider CSR the duty of the private sector (with a few exceptions such as South Korea and Japan). This differentiation derives from cultural understanding, motivation, and socially accepted definitions of what CSR is. Furthermore, G. Williams and Zinkin (2008) use Hofstede's cultural dimensions and suggest CSR experiences, acceptance, and practice may reflect differences in culture alongside institutional differences and society will then punish those organizations that do not conform to acceptable social CSR minimums. For example, in established and industrialized countries of Western Europe high levels of education, technological development, and relative personal wealth foster postmaterialist value that emphasize self-expression, quality of life, and concern of the environment (Furrer et al., 2010). On the other hand, individuals in Central and Eastern European countries are less willing to sacrifice future opportunities to personal prosperity for the sake of social values.

The difference in values across continents is not exclusive to individual attitude. There is also a marked difference between CSR practices in multinational companies (MNCs) and small and medium enterprises (SMEs). According to Raynard and Forstater (2002) the increase of CSR standards and societal expectations may actually undermine SME development in developing countries. For example, without the resources to implement, measure, and evaluate CSR practice Raynard and Forstater suggest the CSR activists may place unreasonable expectations upon business practice. To alleviate such pressures, Perrini (2006) propose that SMEs should focus on social capital-where SMEs are able to capture intellectual capital, strengthen supplier relationships, and facilitate entrepreneurship in the surrounding community. Indeed, the ability to understand the local community is seen as the difference to that of MNCs. Vives (2006) exemplifies this by suggesting that Latin American SMEs are more concerned for their employees and the need to maintain good relations with clients, suppliers, and the community. Interestingly, within Latin America SMEs, CSR can be explained mostly by ethical and religious factors.

Yet it is this voluntary nature of CSR that has increased definitional confusion. Fox (2004) suggests that the development of CSR and the voluntary nature of business practices may dilute a structured agenda. Instead of CSR definitions and ubiquitous standards, Fox suggests building a business environment on human and institutional capacity to generate and respond to more contextualized drivers to help CSR overcome its perception as a PR exercise. As Marrewijk (2003) claims, these diverse CSR standards and guides provide significant confusion as to what is expected of 
companies and how companies go beyond expectations and regulation. For example, a study by McWilliams, Siegel, and Wright (2006) demonstrates Danish companies are more likely to support CSR activities that have a direct effect on the welfare of the local community. While Jamali and Mirshak (2007) found that in Lebanon, companies have uncritically adopted CSR for philanthropic purposes. This acceptance of philanthropy as the panacea of CSR responsibility is in stark disregard to far-reaching social issues such as national productivity, levels of employment, labor rights, enhancing antitrust feeling, and corruption.

While components of CSR are rooted in Western ideology and cultural norms these components are bound to change as emerging markets increasingly dominate world economies. Musgrave (2011) proposes that advocates will have to recognize deeprooted social and business distinctions if they want CSR to continue to influence the global industry. If not, CSR could be seen as of little value to diverse markets. Equally, it could diminish the CSR agenda and get lost in translation.

\section{International CSR Standards}

Although globalization has created global multinational companies with far reaching wealth and influence, Oldenziel and Stichele (2005) propose that these organizations require internationally agreed set of responsibilities/standards in order to be held accountable for the social, environmental, and economic consequences of the activities of corporations including their supply and value chains. Yet, Gössling and Vocht (2007) reported there is still no legally binding code of conduct for MCS or for foreign direct investment. Indeed, Skovgaard (2011) confirms that the EU has firmly rejected a regulatory approach to CSR. For example, the European Strategy 2020 approach is to increase knowledge of the business case for CSR, develop means to sharing best practice, promote CSR managerial skills, and introduce ethical dimensions to procurement policies. Fairbrass (2006) confirms that the major dispute in EU is the way in which CSR is implemented rather than defined. Indeed, as noted earlier, the commission continues to adopt a voluntary code despite pressure from trade unions, environmental, and other social groups.
Although Moon (2004) agrees that CSR is highly contextual, he purports that common themes exist within CSR activities:

- CSR refers to business responsiveness to social agendas in its behavior and to the performance of these responsibilities.

- CSR is seen as philanthropic behavior additional to the main for-profit and beyond requirements of law.

- CSR is about how business performs and not just about its involvements outside the business.

It is apparent that "one size fits all” CSR initiatives do not satisfy all-there are major disputes in the way in which CSR is implemented, reported, and defined. Indeed, a one-sided view of CSR exists that considers profit making, win-win situations, and consensus outcomes in multistakeholder arrangements (Prieto-Carrón, Lund-Thomsen, Chan, Muro, \& Bhushan, 2006). However, important social issues such as role of power in society, class, and gender are infrequently reported. Nonetheless, in taking the societal approach Andrioff and Mcintosh (2001) argue that in reality there are limits to interpretation and terminology that cover all dimensions of a company's impact and responsibilities to society. Without a doubt, an approach towards a contextualized understanding of CSR will establish a changing agenda that attempts to bring together individual business, the impact of CSR initiatives, power, and participation in CSR (Prieto-Carrón et al., 2006). As Musgrave (2011) suggests, CSR must be seen as a concept that is intertwined with internal and external variables with infinite permutations of maintaining environmental commitment allied to organizational values; constant battles towards organizational ethics and behavior in promoting involvement in society.

\section{Conceptual Discussion: \\ Ecological Systems Theory}

The contextual nature of CSR demonstrates the fierce struggle academics and practitioners have in comparing practices, agreeing terminology, and applying parameters. Nonetheless, given the complex nature of CSR the contextual debate does allow the possibility to look elsewhere for answers. 
Rather than ignoring these fundamental variables, a systems view provides an alternative stance and acknowledges the interdependent elements that form a holistic perspective. According to Charlton and Andras (2013), systems thinking argues that complete understanding comes from an acceptance and view of the parts in relation to the whole. Thus it can be argued that CSR has constituent parts (environmental, social, and environmental perspectives) that fit within a wider interdependent context, a view supported by Armsworth et al. (2010). Certainly viewing the constituent parts of CSR and how they relate to the environment is a necessity where Johnson and Wilson (2000) see reality as being socially created at both local and broad societal levels (the structuralism perspective). Thus, attempting to separate CSR from the environment would create artificial context and limit successful implementation of CSR initiatives. These thoughts are also shared by the general systems theory (GST) of organizational behavior, whereby a system approach begins by characterizing an organization's environment; then meet the needs of their environment; exhibit an understanding and acknowledgement of the interdependent environmental layers; a knowledge of where in the environment to find the right inputs, an understanding of what kind of transformation is required and what output to produce. In recognition of such broad lenses, Zineldin (1998) proclaims a GST approach can incorporate cultural psychology through to coconstructionist perspectives and can take on an ecological and collaborative system that allows organizations to learn, adapt, and evolve to changing environmental conditions.

This premise is furthered by taking Moon's (2004) view that CSR is based upon social and human interaction with their environments. Garavan and McGuire (2010) go further, suggesting that CSR involves strong organizational commitment to social obligations inherent within employees and that CSR obligations are mobilized by social compulsions. As Marrewijk (2003) declares, employees and organizations are mutually dependent-organizations support their employees, creating value as an agency, and are in constant exchange with its stakeholders, thus reflect vertical and horizontal communion. With this in mind, human context cannot be restricted simply to the microsystem but must incorporate linkages between the systems from micro to macro. The ways in which these factors are organized or indeed disorganized have a direct impact upon the individual's ability to apply complex issues (macrosocietal and microsocietal) and facilitate CSR interventions in the workplace. It is Karl Marx that describes context as having the ability to facilitate or impede development of such cognizance and action (Inglehart \& Welzel, 2005); thus individuals become the partial products and producers of their own environment. And so humans are at the core of an ecological system within which organizations operate and indeed where corporate responsibility exists.

Yet, in taking a more human perspective systems theory to CSR, additional complications can occur. For example, Cahan (1992) in Tudge, Gray, and Hogan (1997) suggest that understanding the individual alone or the environment alone is counterproductive. Factors such as the immediate social and physical environments cannot be fully understood without being cognizant of the historical, cultural, and social conditions that influence behavior and expectations. Thus the effects of these individual and environmental factors upon CSR expectations and practices vary in strength and direction. Accordingly, and as suggested by Bronfenbrenner (1979) in Lerner (1995), the relation between the factors is synergistic and multidirectional.

Urie Bronfenbrenner is widely recognized (see, e.g., Tudge et al., 1997; Lewthwaite, 2011) for his seminal work in mapping ecological systems theory on human development and furthering the study of human beings and their environment. In Bronfenbrenner's Ecological Framework for Human Development it goes beyond the interactive nature of individuals and their environments (proximal and distal) and mirrors the thoughts of Karl Marx where emphasis is placed upon the person-process-context model and requires cognizance of the way in which individuals are influenced and at the same time influence the context that envelops them. Take, for example, C. A. Williams and Aguilera (2008), who suggest that attitude towards CSR is influenced by national cultural norms, organizational culture, or industry norms. They go on to suggest that cross-national studies by Donaldson and Dunfee (1999) also evidence an extension of social contract theory whereby fundamental principles, such as acceptance of excessive 
working hours, are constant yet local norms vary and are dependent upon stages of industrialization and industry sector norms. These findings suggest a dichotomy of experiences that consumes the surrounding environment yet also assists in creating the surrounding environment.

It can be seen that human interpretation, perspectives, and sense of reality is the root cause of CSR success, likewise the root cause of failure. But in applying the constructs of Bronfenbrenner's Ecological Framework for Human Development one can reflect upon the role of human interaction with both proximal and distal environments and systematically reveal how these environments influence CSR implementation and practice within organizations.

Taking Bronfenbrenner's framework, the components of an Ecological Framework for CSR Understanding (Fig. 2) are theorized as:
- Microsystem: The internal setting in which the organization emerges/operates/exists. These factors relate to individuals and their circumstances within an organization, how individuals observe their own roles, the relations between the person and those around him/her within the organization.

- Mesosystem: This level represents the extent of influence the interpersonal relations (microsystem) have upon personal values and CSR activities within the organization. The complex interdependence between one set of people and another can establish inconsistencies in organization reaction or action.

- Exosystem: There are many contexts with which the organization does not have direct contact but nevertheless exert influence. These are identified as industry, local and national media, local community, local politics, and social services. These

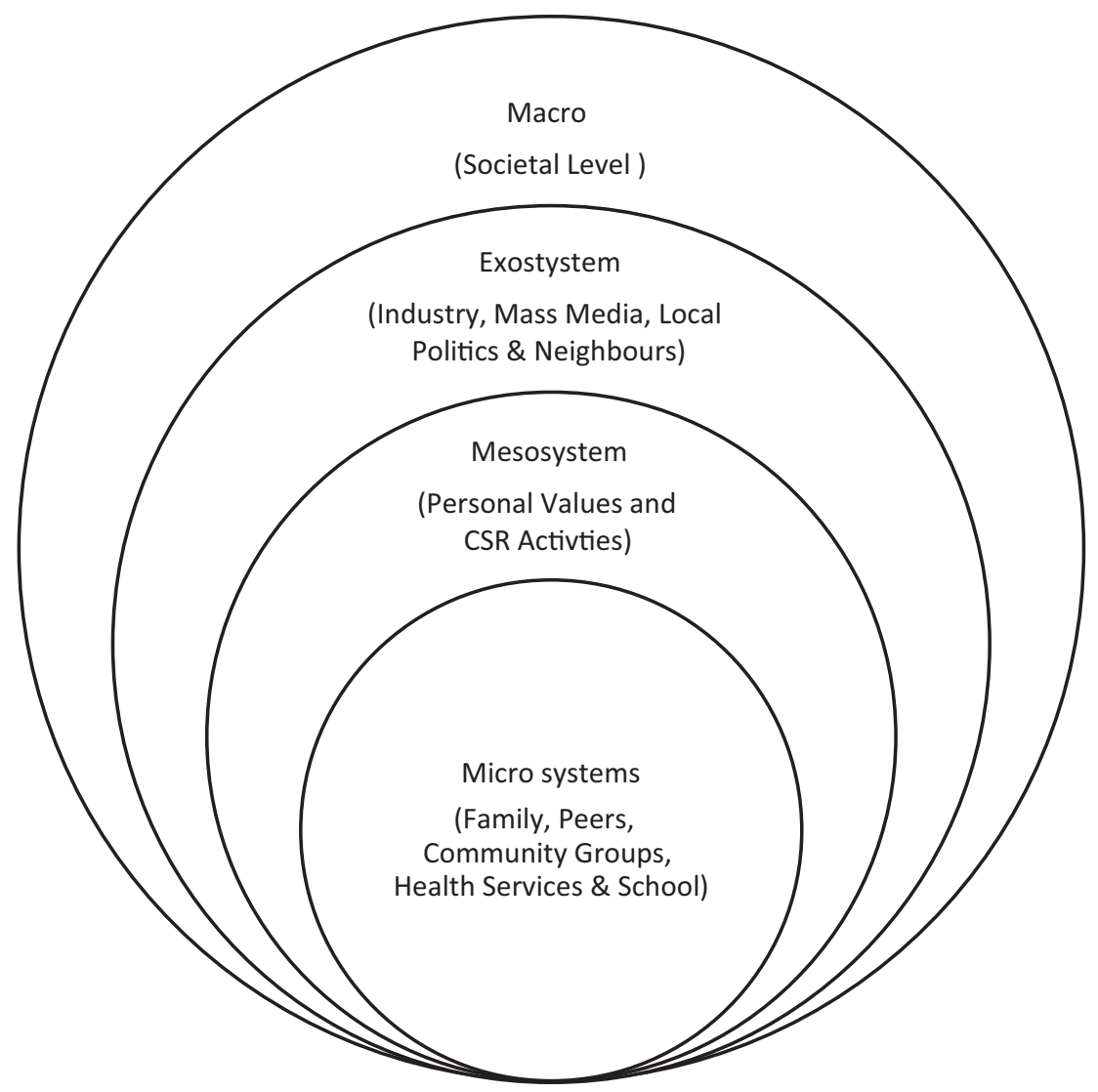

Figure 2. Ecological framework for CSR understanding. Adapted from Tudge et al. (1997). 
groups influence social norms and expectations related to CSR within local parameters.

- Macrosystem: These broad effects are those at the societal levels including social class, race and ethnicity, belief and value systems, cultural tools, and institutions. For example, these broad sets of factors can determine CSR and political will, levels of accepted behavior, and legal agenda, albeit indirectly.

As suggested earlier within the article, applying practices of CSR onto an ecological systems theory framework will help underline the contextual debate surrounding CSR and how such contextual constructs influence practices of meeting planners. Finally, this will help towards understanding why uptake and practice of CSR is variable across the sector.

\section{Method}

A database of potential interviewees was created via invitation to a professional global network of over 20,000 meeting planners. Potential respondents were sent a request for interview and if this invitation was accepted, the interview was conducted either over the telephone or using Skype. Ninety interviews were arranged. A semistructured interview technique was used to ensure all key issues were tackled but allowing respondents the freedom to explore issues in as much detail as they wished to provide (Veal, 2006). Respondents answered a range of questions pertaining to the extent of their personal and corporate involvement in CSR, the motives behind their personal and their organization's involvement in CSR, existing CSR initiatives and practices, and future intentions.

Both authors applied a constant comparison process as outlined by Hancock, Ockleford, and Windridge (2009) in order to establish a rigorous audit trail of analysis. Initial coding was conducted by both authors, with higher-order themes derived from the CSR and environmental management literature followed by progressive process whereby patterns and themes were discovered in the data and a coding scheme was developed. Eight codes were identified and the coding frame was systematically applied using NVivo software across the 90 interview transcripts by the lead author. After reflection of the coding frame, each code was given a name that represents the practices under each code: Green Technology, Legislation, Transparency and Reliability, Nonfinancial Donations, Workforce, Community Engagement, Supply Chain Management, and Volunteer Labor.

In no particular order, meeting planner's practices will be discussed in the following section and applied to the constructs of an ecological systems theory.

The analysis does not claim to provide a panacea of CSR practice across the global meetings sector. Rather, it offers an insight into the engagement and practice of CSR by meetings industry professionals and places these practices within the broader context of a conceptual ecological systems theory. These can be seen in Figure 3.

\section{Findings}

\section{Community Engagement}

There is a strong discourse towards community involvement in the results, exemplifying the importance of social norms and demonstrating salient “exosystem” concerns. For example, meeting planners consider themselves as intermediaries that consume local suppliers to produce events and as such see community engagement as paramount. One participant suggests that "CSR means making contributions of your time and talent and resources to community service activities that are good for the community" and "it's important for a corporation to show its commitment to the community where it operates. It's important for the morale of the employees who work at the corporation.” This final comment is often seen where CSR means taking "action on behalf of the organization" and "the people" that meeting planners are serving.

These social norms emerge from awareness and focus upon local concerns demonstrated through local media, local community groups, and awareness of such issues and then processed in the mind of employees and employers. This wider view of the influence meeting planners have on their community is further reinforced by other participants who suggest that the business of meetings also means "making good quality decisions that positively affect our community on both minor and major levels," thus highlighting what Ziakas (2014) refers to as leveraging events for political and economic regeneration of place. Indeed, 


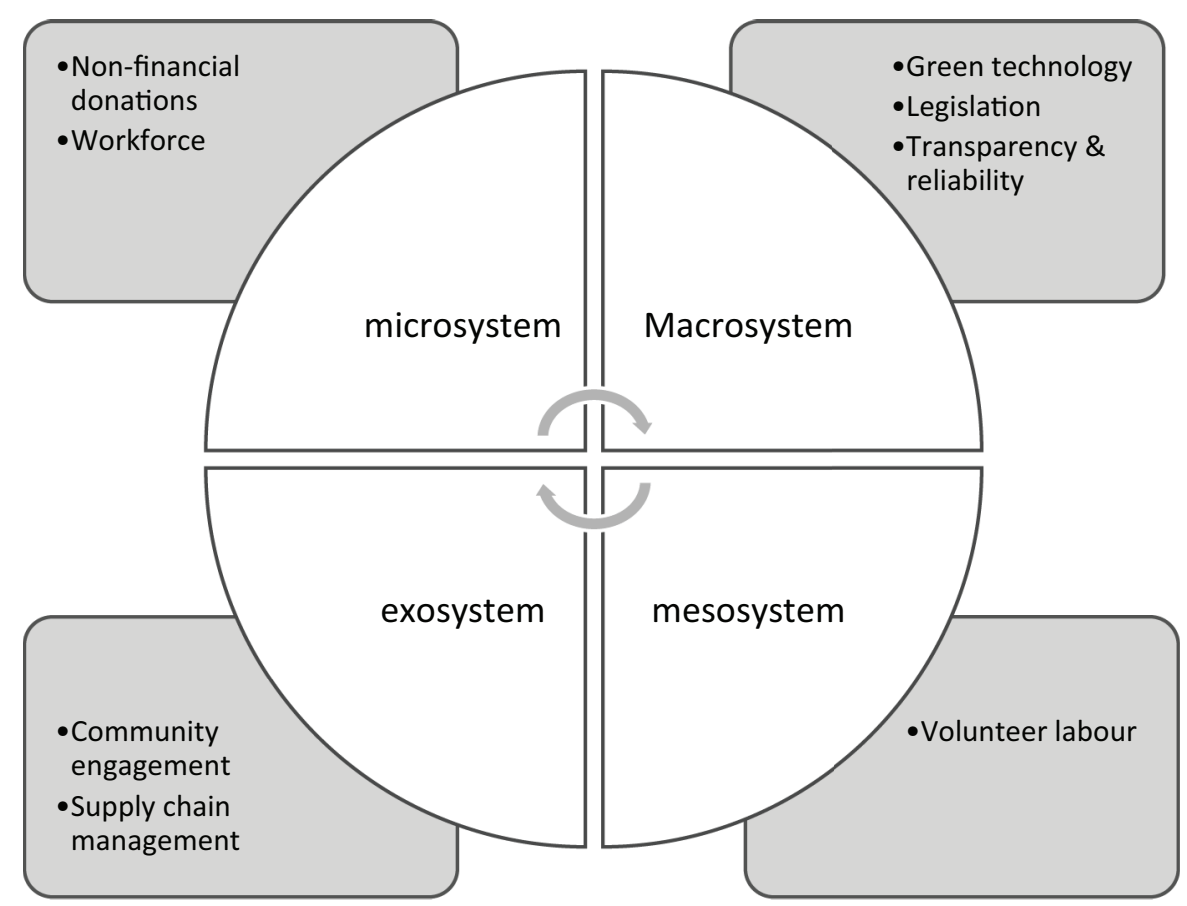

Figure 3. Meeting planner's perspectives mapped against an ecological systems theory of CSR.

this also refers back to traditional economic views of what constitutes organizational responsibility. However, going beyond the traditional view of economists dominates the view of CSR from a meeting planner's perspective:

The organization wanted to help staff members with families. It started with an after-hours care for children, and evolved into tutoring. Then we realized there were families with special needs: patients requiring blood transfusions have a very hard time getting donors, incidences of cancer, children and young adults with developmental challenges. In a similar vein, we work with outreach programs to help improve the lives of local people.

These local stories are repeated throughout the results:

Lately my company has been involved in serving breakfast to kids who go hungry at school. It's half an hour on a morning and it's very gratifying to see the kids happy with their tummies full.

One participant summed up a recurring stance that "you need two very important things; you need to be part of a community and you need to be aware of what's happening in social, political, economic and technical aspects of society."

What is evident from the combination of responses is that it is the idea of servitude and giving back to the local community engenders a sense of corporate responsibility within the minds of these meeting planners. The range of practices differs, but it is the relationships between themselves as individuals and their community that inspires initial CSR practices. Prior to engaging with these local issues, no relationship existed and it is argued that through awareness, empathy, and understanding of local concerns, the CSR activities started to emerge.

\section{Volunteer Labor}

It is proposed that the practice of volunteer labor sits within a mesosytem of CSR activities. This level represents the extent of influence the interpersonal relations (microsystem) have upon personal values and CSR activities within the organization. This is exemplified well by meeting planners who refer to their CEO's belief systems: "Our CEO has a strong 
belief in CSR. He tries to help each employee find a place to volunteer their time outside of work.”

Within this category, the value of CSR is focused internally within the business, and the value the business attaches to volunteering as a CSR activity. For example, "We give our employees time to serve on boards for non-profits and industry associations" and others purport "Volunteerism plays a big role in CSR" and "The volunteerism meets our values as we meet our own human needs to contribute. It encourages staff to stay longer with us and contributes to our well-being."

These particular contributions make reference to mesosytem characteristics where individuals observe their own roles, the relations between the person and those around him/her within the organization. It appears within this sample of meeting planners that volunteer labor is a resource that moves beyond the more philosophical stance of community engagement and reaffirms their own role within their local community through CSR practice.

\section{Legislation}

At a macrosystem level, accepted behavior is determined by broad societal factors (Johnson \& Wilson, 2000) and enforced by legislation. Equally, this can be traced to levels of responsibility expected of business (Falck \& Heblich, 2007). For example, Málovics et al. (2009) categorize CSR into "must responsibilities" that are couched in legal minimums, "should responsibilities" that are derived from societal norms, and "can responsibilities" that move beyond legal minimums and social expectations. Yet meeting planners are increasingly frustrated with the constraints derived from the attainment of legal minimums and the misplaced expectations from consumers. For example, meeting planners have been castigated for their excessive food waste in recent years, yet legally they have been restricted:

When there is food left from a buffet for 200 we would love it to go to charity. However, the regulation does not allow us to do that. The only thing we can do is invite groups of homeless to dinner. That only happens in rare cases when the clients insist.

These exemplify the concerns of Raynard and Forstater (2002), where societal expectations may place unreasonable pressure on businesses. This is furthered by Spitzer (2009), where understanding of CSR differs from country to country, equally legislation does too. Consequently, CSR practice of event planners may not meet expectations of society-not due to a lack of legislative adherence but primarily because of legislative adherence and a lack of understanding from attendees.

\section{Nonfinancial Donations}

Nonfinancial donations are placed within this section as these CSR activities relate directly to individual contributions and corporate donations. Whether or not these nonfinancial donations are a substitute for concerns over social issues cannot be assessed within the study.

Two subgroups emerge from the results. First, donations are seen as a complete philanthropic transaction with little reflection or indeed little interaction beyond the act of donating. This approach reflects comments by Jamali and Mirshak (2007), where certain countries uncritically adopt philanthropy as the extent of CSR responsibility. For example, "we collect donations of nonperishable food items" and "we ask for nonfinancial donations on a regular basis and give to local charities." There is a dominance of the words nonfinancial donations within the responses and this is also linked to a personal moral stance: "it is our responsibility to donate to those less fortunate. At company $\mathrm{Z}$ we contribute to food packs for the homeless regularly."

In the second subgroup, donations are seen as a development of status and in application to the systems theory, perception and how individuals observe their own role between the person and those around him/her are key characteristics of this subgroup theme. "Collecting donations of nonperishable foods from our clients and suppliers are then passed on to a local food bank for distribution to those in need for housing project." "In a conference I was at recently they were collecting for a homeless charity 'Dress for Success,' asking for donations of 'gently worn suits' which can be used by people going for interview."

These examples show a more considered approach to their donations and offer personal value beyond the act of donating. Interestingly, these value drivers to donate tend to link back to aspects of business and 
to furthering the rehabilitation of individuals through job interviews, education, or housing.

\section{Green Technology and Environmental Practice}

Results show the consistent use of technology to assist in the reduction of energy use and carbon emissions. Paradoxically, the question of "needing to meet at all” reflects the current state of mind and worry for many meeting planners.

At a meeting planner level it was found that "One of our most successful economic and environmental initiatives was swapping vehicles to more fuelefficient cars - we have saved thousands of dollars and reduced carbon costs too." Other meeting planners focused upon the characteristics of the sector suggesting "demanding more efficiency in hotels where it does not only look good, it functions well and it is also environmental.”

When referring to their CSR activities many meeting planners mention their "green" facilities. For example, "we now harvest rain water using modular technology which is very easy to install and maintain and safety wise very appropriate."

When meeting planners consider new builds or refurbishment, standards and certification is considered: "Energy efficiency is very important to us. When we build or replace items in the venue we consider efficient, long life and recycled options, as well as LEED certification standards.”

In relation to venues, meeting planners also consider location and local infrastructure. For example:

It makes perfect business sense to promote our superb rail access to European delegates as well as to the local market. Congress participants use also the public transportation system during their events. It is easy and of course it's a greener mode of transport.

These practices reflect the macrosytem level of CSR understanding where broad social norms and expectations related to CSR practice are at the forefront of meeting planners and are used to determine business decisions. At the same time meeting planners have looked at ways to change their working practices in line with changing societal expectations. For example, "Virtual servers use a lot less space and power. That was a big step for us" and "For instance, we use mobile apps rather than paper where possible ... we also like to print on demand so attendees don't print badges for people who don't show up."

The broad use of green technology and practices within the role of the meeting planner is summed up here:

We have electric plug in stations, we have recycling, and we have all of the things that go with being socially responsible towards sustainability and green. And we don't just care about it as people, we care about it as people who have created products.

Although common themes of recycling are found within the responses, such as "we reduce landfill contributions by composting food waste and by purchasing recyclable or biodegradable product," there is clear chasm between meeting practitioners and with those just starting out: "Baby steps are needed to improve our carbon footprint. Getting rid of plastic cups, improving our paper recycling, trying to reduce our electricity use are our baby steps.”

\section{Supply Chain Management}

The inherent use of the supply chain presents one of the most consistent response patterns in the findings. Supply chain management reflects characteristics from the exosystem level where CSR sits within local parameters where organizations exert influence through a variety of channels. This CSR approach is furthered by the influence of the mesosystem derived from organization cultures and interpersonal relationships. For example, "It made sense to support the local economy, buying locally, reducing carbon footprint as a result and developing better relations with the community" and "conserving energy simply makes sense; recycling and using improved technology to obtain and dispense drinking water; preserving the natural beauty in the area required water treatment and more efficient sewage disposal. A good idea became a way of life.” And it is the combination of internal values and the relationships with local community that is revealed throughout the responses: "Our actions and scope of responsibilities was a partnership through discussion and innovation with our corporate and community suppliers to make our center reduce impacts in all aspects of CSR.” 
The commercial value of these practices are evidently clear, yet the synergy of personal and business values (exosystems and mesosytems) for many meeting planners allows for ethical trading and echoes Wan-Jan's (2006) suggestion of sustainable and ethical profitability. For example, "Our new head of CSR is pushing the company to do more with our suppliers-many of the RFP's we respond to ask if we have a CSR policy. It influences rather than drives supply chain management decisions."

Differentiation within the service sector is also reflected through the supply chain: "There is a lot of competition around here for corporate events and we think buying from local farmers in this way gives us a competitive advantage.” The responses present a positive image of CSR and supports the assumption that adherence to CSR principles will achieve differentiation and profitability and, as suggested earlier, links the business interest with local and personal values. This is summarized well by one participant who suggests that "CSR is about localization. I get more control through working with local businesses and using local ingredients and produce. Local people like this and I can make sure that I know where the foods are from.”

\section{Workforce}

At the more microlevel of the systems approach the "workforce" is revealed as an influential category in CSR practice. Here the respondents cut across organizational theory and reveal CSR principles influence role development, relationship management, and the pluralist view of organization cultures. For example, "Our credibility with the pool of people and the staff that work for us is imperative and I also feel that our credibility with the client is equally important, taking what responsibility we can is part of who we are.” Responsibility and the humanistic approach to people management is reflected in other participants where value comes from seeing "so many people flourish through growth and success."

CSR practices within the workforce is also seen as a conduit to professionalism within the industry itself, where one participant suggests "CSR is absolutely key to retention and an absolute key to moving this industry forward."

The benefits of such working practices are varied and touch upon more than the bottom line. "We are providing a healthier workforce, you know, that has less insurance, or other fees that are directly affecting the bottom line of the organization.”

The relationship between people and the personal setting is also reflected here. One participant suggests that "CSR has a role to play in all functions of organization-leveraging organizational domain expertise for the purpose of creating value and quality of life in the organization.”

Moreover, others have suggested taking a common sense approach to resource allocation: "CSR is more about not abusing resources, looking after the people around you including employees, local suppliers and our clients" but also matching resource allocation with local knowledge. "When it comes to meetings, I definitely try to be cognitive of the fact of location: do I need to provide transportation or is it walkable.” Once again the diverse attitudes towards the extent of CSR and its use in the workforce exemplifies the contextual nature of CSR and firmly places CSR in a pluralist paradigm.

\section{Transparency and Reliability}

One of the more contemporary issues within the participant responses is trust and brand reputation. Evidently CSR plays a vital role in the transparency of business practices for meeting planners and shows reliability of service. For example,

\section{I make sure that all clients know everything upfront, I don't keep anything hidden. In this day and age it doesn't make sense to hide anything, it makes more sense to say this is what you want, this is what you're going to get and this is how it is costed out.}

The macrosocietal concern of meeting planners also exemplifies how national concerns can influence local practice. These macroissues seem to dominate the thoughts of meeting planners when they relate business practice to CSR: "much of social responsibility is around religion, money, and politics, or at least moral direction, economics, and politics. It certainly makes an environment in which you need to be conscious and clear of what you are doing."

Transparency and reliability also reflects components of CSR at an international level where certain participants see CSR as a divisive and sensitive subject to bring into a conversation: 
CSR can be a very sensitive area for some people, because social responsibility implies society, and how society is, by definition, a very diverse and very mixed and very culturally different environment. One person's acceptable behavior is another's unacceptable behavior.

The idea that meeting planner's responsibility should move beyond profit is often cited in the findings and is reflective of the classic societal approach to business. For example, “. . . taking the position of your business in the world seriously. There is more to doing business now than simply making profit." Yet there is division as to how meeting planners implement such thoughts. For example, one participant suggests a cohesive and long-term strategy that is explicit from the outset:

If you think of CSR in terms of a long-term growth strategy and you do it properly, if you align your CSR with what your customers expect and what your employees expect, then you can get long-term growth and get tremendous revenue opportunities.

Being transparent and what constitutes reliability for meeting planners is not standardized but naturally shows an awareness and suitability towards the surrounding proximal and distal environments. Although there is an underlying variance in practice, the overarching premise of each practice refers to Schwartz and Carroll (2003), where investment in CSR can be seen as a mechanism for product differentiation and through exploitation of the appeal of CSR attributes, impacts upon niche markets.

\section{Discussion and Research Implications}

In recognizing a systems approach to CSR there is an acceptance that there isn't one best method and that different values, implementation approaches, and evaluation mechanisms of CSR can lead to similar results. An ecological framework that pins context as the central factor of practice and understanding may encourage greater acceptance of national and international CSR management standards and measurement. For example, ISO 2012-Event Sustainability Management systems advocates flexibility and recommends "an understanding of the organization's context' in determining sustainable issues and to improve the likelihood of successful implementation of CSR practices."

This is an important shift. For example, a recent study into the importance and value of CSR in the meetings sector (Musgrave et al., 2012) showed that only $10 \%$ of meeting planners intended to implement an accredited management standard such as ISO 2012, GRI Event Organizers Sector Supplement, or ISO 26000. This statistic reflects the short termism and checklist-oriented mindset that dominates practice within the sector. Although the use of internationally recognized frameworks is seen as best practice they are seen as overwhelming and costly to practitioners. Conversely, checklists narrow understanding yet they are seen as quick, inexpensive, and achievable. Nevertheless, having the skills and the ability to measure the performance of CSR practices and more importantly, knowing the context of such analysis, will enable decisions that are more suitable and of value to the meeting planner in the long term. For example, the development of strong community engagement or transparency and reliability towards supply chain management provides an opportunity for differentiation, staff self-fulfillment, and enhanced responsiveness. And it is the articulation of value to the meeting planner that is critical to changing business practice.

The dissention between short-term and longterm value is not exclusive to the meetings industry but given the brevity of events it is more acute as consumers and practitioners alike enjoy the instant gratification of results that encompass the experience economy. In spite of this short-term fulfillment, longer-term trends are set to impact on businesses and CSR can support businesses to meet new challenges such as contraction of reliable suppliers; the focus on return on meetings outcome and the changing expectation of consumers as Gen Y move into key buyer stages of their life cycle. Consequently, an ecological framework for CSR may further understanding and allow practitioners to view trends that are CSR related as part of a holistic approach that can add value and reflect the development of value creation and offer guidance on how to make CSR economically worthwhile to meeting planners.

As Prierto-Carrón et al. (2006) propose, this shift in thinking enables an explanation of what works in one context as opposed to another. Indeed, using the 
four constructs of the ecological framework for CSR understanding (micro, meso, exo, and macrosystem) as a starting point of analysis may assist in exploring the nature and consequences of CSR for meeting planners within and outside the organization. For example, it can explore who is addressed or overlooked in existing CSR interventions or help assess the suitability and acceptability of new CSR strategies in relation to proximal and distal environments.

Yet assessing the suitability and acceptability of CSR approaches requires a true stakeholder analysis. It is suggested that using the ecological framework for CSR understanding as an analytical tool may allow for a more localized understanding while providing a true stakeholder analysis. This approach reflects the thoughts of Moon (2004) and Garavan and McGuire (2010), where CSR is based upon social and human interactions. And as a result of advanced capitalism, globalization, and an increasing transient workforce, modernity and postmodern society exist in parallel, intertwined within regional and national cultures. So far from being harmonious these scenarios offer a range of possibilities such as a greater number of social roles, individualism and increased tension, misinformation, and expectation conflict (Andrews \& Leopold, 2013). Placing CSR within this framework and through a different lens may place the mindset of meeting planners beyond the societal approach to CSR and better serve the need and satisfaction of diverse societies (local, regional, national, and international) and reflect the range of possibilities that modern society has created.

\section{Conclusion and Limitations}

There are marked differences of CSR practice at national and international level, within SMEs and MNCs. These practices are influenced from macro and microsocietal characteristics such as social norms, religious connections, local regulation, and national legislation. CSR is also based upon human interaction with environments and this presents difficulties in developing minimum standards and establishing accepted behaviors. Although recognizing these variables, a general systems theory acknowledges these interdependent elements and places the organization at the heart of the contextual CSR debate.
By combining the elements of CSR principles it can be argued that CSR needs to be placed within a system that recognizes human perspectives. Using Bronfenbrenner's seminal work to outline CSR understanding, it shifts analysis and thinking towards context and relationships as the founding principles of accepted practice and behaviors. From a meeting planner's perspective, it goes beyond the short termism of checklist-orientated approaches and may encourage acceptance of national and international CSR management standards. Moreover, the ecological systems approach attempts to provide insight into true stakeholder analysis and identify value items placed upon CSR practice.

The emergence of such thinking strengthens the argument of flexibility within CSR practice and broadens the acceptance of what constitutes acceptable and suitable CSR parameters.

Moving beyond the obvious limitations of a conceptual article, there are some unique issues in applying and testing the framework through empirical work. First, the contextual nature of this article and subsequent conceptual framework favors a case study approach to testing the four constructs of the ecological framework for CSR understanding and applying it to CSR practices.

Nonetheless, comparisons will be difficult to map and measure as context is the fundamental driver and barrier to further work. As the literature argues, it is people within organizations and institutions rather than imposed policy that determines CSR practice. For example, respondents from the US reflect a society with a limited social welfare system.

Moreover, the constant comparison method has various opportunities for bias while using authors to initially code the findings. Coupled with a purposive sample there are additional areas of bias. A more systematic methodology will enhance further development.

\section{Acknowledgments}

The authors would like to thank Jackie Mulligan and Dr. Alexandra Kenyon for also undertaking interviews as part of the original wider study into the value of CSR in the meetings sector. Moreover, the authors would like to thank MPI Foundation and Intercontinental Hotel Group for their support 
in the original study. Finally, the authors would like to thank the interviewees for their participation.

\section{References}

Andrews, H. \& Leopold, T. (2013). Events and social sciences. Abingdon, UK: Routledge.

Andriof, J., \& McIntosh, M. (Eds.) (2001). Perspectives on corporate citizenship. London: Greenleaf Publishing.

Armsworth, P. R., Armsworth, A. N., Compton, N., Cottle, P., Davies, I., Emmett, B. A., \& Shannon, D. (2010). The ecological research needs of business. Journal of Applied Ecology, 47(2), 235-243.

Banerjee, S. B. (2008). Corporate social responsibility: The good, the bad and the ugly. Critical Sociology, 34(1), 51-79.

Carroll, A. B. (1999). Corporate social responsibilityevolution of a definitional construct. Business Society, 38(3), 268-295.

Chapple, W., \& Moon, J. (2005). Corporate social responsibility (CSR) in Asia: A seven-country study of CSR web site reporting. Business \& Society, 44(4), 415-441.

Charlton, B. G., \& Andras, P. (2013). What is management and what do managers do? A systems theory account. Philosophy of Management, 3(3), 3-15.

Dahlsrud, A. (2008). How corporate social responsibility is defined: An analysis of 37 definitions. Corporate Social Responsibility and Environmental Management, 15(1), $1-13$.

Donaldson, T., \& Dunfee, T. W. (1999). Ties that bind: A social contracts approach to business ethics. Boston, MA: Harvard Business Press.

Fairbrass, J. (2006). UK businesses and CSR policy: Shaping the debate in the EU. Bradford, UK: University of Bradford, School of Management.

Falck, O., \& Heblich, S. (2007). Corporate social responsibility: Doing well by doing good. Business Horizons, 50(3), 247-254.

Fox, T. (2004). Corporate social responsibility and development: In quest of an agenda. Development, 47(3), 29-36.

Friedman, M. (1962). Capitalism and freedom. Chicago, IL: University of Chicago Press.

Furrer, O., Egri, C. P., Ralston, D. A., Danis, W., Reynaud, E., Naoumova, I., Molteni, M., Starkus, A., Darder, F. L., Dabic, M., \& Furrer-Perrinjaquet, A. (2010). Attitudes toward corporate responsibilities in Western Europe and in Central and East Europe. Management International Review, 50(3), 379-398.

Garavan, T. N., \& McGuire, D. (2010). Human resource development and society: Human resource development's role in embedding corporate social responsibility, sustainability, and ethics in organizations. Advances in Developing Human Resources, 12(5), 487-507.

Gössling, T., \& Vocht, C. (2007). Social role conceptions and CSR policy success. Journal of Business Ethics, 74(4), 363-372.

Hancock, B., Ockleford, E., \& Windridge, K. (2009). An introduction to qualitative research. Sheffield, UK: The
NIHR Research Design Service for Yorkshire \& the Humber.

Inglehart, R., \& Welzel, C. (2005). Modernization, cultural change, and democracy: The human development sequence. Cambridge, UK: Cambridge University Press.

Jamali, D., \& Mirshak, R. (2007). Corporate social responsibility (CSR): Theory and practice in a developing country context. Journal of Business Ethics, 72(3), 243-262.

Johnson, H., \& Wilson, G. (2000). Biting the bullet: Civil society, social learning and the transformation of local governance. World Development, 28(11), 1891-1906.

Katsoulakos, P., Koutsodimou, M., Matraga, A., \& Williams, L. (2004). A historic perspective on the CSR movement. CSRQuest Sustainability Framework. Retrieved from http://www.csrquest.net/uploadfiles/1D.pdf

Ketola, T. (2007). A holistic corporate responsibility model: Integrating values, discourses and actions. Journal of Business Ethics, 80, 419-435.

Lerner, R. M. (1995). The place of learning within the human development system: A developmental contextual perspective. Human Development, 38(6), 361-366.

Lewthwaite, B. (2011). University of Manitoba Centre for Research in Youth, Science Teaching and Learning: Applications and utility of Urie Bronfenbrenner's bio-ecological theory. Manitoba Education Research Network (MERN) Monograph Series (4), University of Manitoba, Winnipeg, Manitoba, Canada, pp. 3-14.

Málovics, G., Csigéné, N. N., \& Kraus, S. (2008). The role of corporate social responsibility in strong sustainability. The Journal of Socio-Economics, 37(3), 907-918.

Marrewijk, M. (2003). Concepts and definitions of CSR and corporate sustainability: Between agency and communion. Journal of Business Ethics, 44(2-3), 95-105.

McWilliams, A., Siegel, D. S., \& Wright, P. M. (2006). Corporate social responsibility: Strategic implications. Journal of Management Studies, 43(1), 1-18.

Merrilees, B., \& Marles, K. (2011). Green business events: Profiling through a case study. Event Management, 15(4), 361-372.

Montiel, I. (2008). Corporate social responsibility and corporate sustainability separate pasts, common futures. Organization \& Environment, 21(3), 245-269.

Moon, J. (2004). Government as a driver of corporate social responsibility: The UK in comparative perspective. Retrieved from http://195.130.87.21:8080/dspace/ bitstream/123456789/1102/1/20-Government\%20as \%20a\%20Driver\%20of\%20Corporate\%20Social\%20 Responsibility\%20The\%20UK\%20in\%20Compara tive\%20Perspec.pdf

Musgrave, J. (2011). Moving towards responsible events management. Worldwide Hospitality and Tourism Themes, 3(3), 258-274.

Musgrave, J., Mulligan, J., Woodward, S., Kenyon, A., \& Jones, S. (2012). The value of CSR in the meetings industry study report. Retrieved from http://www.mpiweb.org/ Publications

Oldenziel, J., \& Stichele, M. (2005). Trade and the need to apply international corporate social responsibility 
(CSR) standards. Retrieved from http://www.eldis.org/ go/home\&id=32634\&type=Document\#.V5pQyrgrLIW

Perrini, F. (2006). SMEs and CSR theory: Evidence and implications from an Italian perspective. Journal of Business Ethics, 67(3), 305-316.

Prieto-Carrón, M., Lund-Thomsen, P., Chan, A., Muro, A. N. A., \& Bhushan, C. (2006). Critical perspectives on CSR and development: What we know, what we don't know, and what we need to know. International Affairs, 82(5), 977-987.

Raynard, P., \& Forstater, M. (2002). Corporate social responsibility: Implications for small and medium enterprises in developing countries. Retrieved from http://www.unido. org/fileadmin/import/29959_CSR.pdf

Rees, T. (2002). The politics of mainstreaming gender equality. In E. Breitenbach, A. Brown, F. Mackay, \& J. Webb (Eds.), Changing politics of gender equality (pp. 45-69). Basingstoke, UK: Palgrave.

Schwartz, M. S., \& Carroll, A. B. (2003). Corporate social responsibility: A three-domain approach. Business Ethics Quarterly, 13(4), 503-530.

Spitzer, E. (2009). Corporate social responsibility (CSR). Doctoral dissertation, University of Vienna, Vienna, Austria.

Skovgaard, J. (2011). EU policy on CSR. In The DRUIDDIME Academy Winter 2011 Ph.D. Conference, January 20-22, Aalborg, Denmark.

Stubbs, W., \& Cocklin, C. (2008). Teaching sustainability to business students: Shifting mindsets. International Journal of Sustainability in Higher Education, 9(3), 206-221.

Tinnish, S. (2013). Keeping up with standards in the new year. Retrieved from http://chicagompi.org/2013/01/ keeping-up-with-standards-in-the-new-year/

Tudge, J., Gray, J., \& Hogan, D. M. (1997). Ecological perspectives in human development: A comparison of Gibson and Bronfenbrenner. In J. Tudge, M. J. Shanahan,
\& J. Valsiner (Eds.), Comparisons in human development: Understanding time and context (pp. 72-105). Cambridge, UK: Cambridge University Press.

UFI. (2012). Global exhibition industry statistics research projects [online]. Retrieved from http://www.ufi.org/ wp-content/uploads/2016/01/2014_exhibiton_industry_ statistics_b.pdf

Veal, A. J. (2006). Research methods for leisure and tourism: A practical guide. Essex, UK: Prentice Hall/Financial Times.

Vives, A. (2006). Social and environmental responsibility in small and medium enterprises in Latin America. Journal of Corporate Citizenship, 21, 39-50.

Wan-Jan, W. S. (2006). Defining corporate social responsibility. Journal of Public Affairs, 6(3-4), 176-184.

Williams, C. A., \& Aguilera, R. V. (2008). Corporate social responsibility in a comparative perspective. In A. Crane, D. Matten, A. McWilliams, J. Moon, \& D. S. Siegel (Eds.), Oxford handbook of corporate social responsibility (pp. 452-472). Oxford, UK: Oxford University Press.

Williams, G., \& Zinkin, J. (2008). The effect of culture on consumers' willingness to punish irresponsible corporate behaviour: Applying Hofstede's typology to the punishment aspect of corporate social responsibility. Business Ethics: A European Review, 17(2), 210-226.

Ziakas, V. (2014). Planning and leveraging event portfolios: Towards a holistic theory. Journal of Hospitality Marketing \& Management, 23(3), 327-356.

Zineldin, M. A. (1998). Towards an ecological collaborative relationship management: A “co-opetive” perspective. European Journal of Marketing, 32(11), 1138-1164.

Zink, K. J. (2007). From total quality management to corporate sustainability based on a stakeholder management. Journal of Management History, 13(4), 394-401. 